\title{
A review of the techniques used to characterize laser sintering of polymeric powders for use and re-use in additive manufacturing
}

\author{
Fredrick Mulinge Mwania*, Maina Maringa, and Jacobus G. van der Walt \\ Central University of Technology, Faculty of Engineering, Built Environment and Information Technology, Department \\ of Mechanical and Mechatronics Engineering, Private Bag X20539, Bloemfontein 9300, South Africa
}

Received: 4 December 2020 / Accepted: 6 April 2021

\begin{abstract}
Additive manufacturing (AM), is one of the key components of the 4th industrial revolution. Polymer laser sintering (PLS) is a subset of AM that is commonly used to process polymers, and which achieves good surface finish, good mechanical properties of finished products and for which there is no need for support structures. However, the requirements for polymeric powder for PLS are strident. Moreover, PLS subjects polymeric feed powders to high temperatures that lead to degradation of their thermal, rheological, and physical properties and is thus an impediment to their recyclability. Therefore, it is imperative to investigate the degree of polymer degradation or aging before re-using the material. This paper reviews the common techniques that are employed to characterize the suitability of polymeric powders for use and re-use in the PLS process. These include, but are not limited to, differential scanning calorimetry (DSC), thermogravimetric analysis (TGA), laser diffraction analysis, gas pycnometry, scanning electron microscopy (SEM), and melt flow index (MFI) testing.
\end{abstract}

Keywords: Additive manufacturing / characterization of LS polymeric powder / re-use of polymeric powder / LS

\section{Introduction}

According to ASTM standard (ASTM F2792-12a), additive manufacturing (AM) is described as a set of technologies that are utilized to generate $3 \mathrm{D}$ parts from computer data, usually by adding layer upon layer of material, as opposed to the subtractive methods that involve removal of material during the fabrication process [1]. The technology is one of the major components of the 4th industrial revolution [2]. As a result, significant research has been channeled towards various AM technologies. Polymer laser sintering is a subset of additive manufacturing technologies. The PLS process involves the consolidation of material powder with the use of laser energy [1]. This AM technique is one of the most promising technologies for processing polymers because of its capability to print components with excellent surface finish, good mechanical properties, high durability and high dimensional accuracy. Moreover, the process does not require support structures as the powder provides this, which eliminates the need for post-processing upon

\footnotetext{
* e-mail: fredmulinge@gmail.com
}

removal of the printed part [3]. Uptake of the method is, however, obstructed by a limited variety of applicable polymers. The dearth of a wide array of PLS polymeric materials is attributed to the stringent processing conditions as well as material-property requirements of the process [1]. The processing conditions of PLS include optimum process-chamber temperature, suitable extraction-chamber temperature, appropriate scanning speed and laser power [4]. Moreover, polymers for the PLS process should have acceptable intrinsic and extrinsic properties [1]. Intrinsic characteristics include thermal, rheological and optical properties, whereas the extrinsic attributes encompass particle size, particle morphology and powder density [1]. These conditions and requirements have contributed to the limited palette of polymeric materials available for the PLS process. Of the PLS polymeric materials available, $90-95 \%$ are either polyamide 12 (PA 12), polyamide 11 (PA-11), or their blends [5]. The balance are polymers such as polypropylene (PP), polyether ether ketone (PEEK), polyethylene (PE), thermoplastic elastomers (TPE), and polyurethanes (PU), as represented in Figure 1 [1]. Therefore, there is a need for more research to be carried out to broaden the choice of polymeric materials for PLS. 


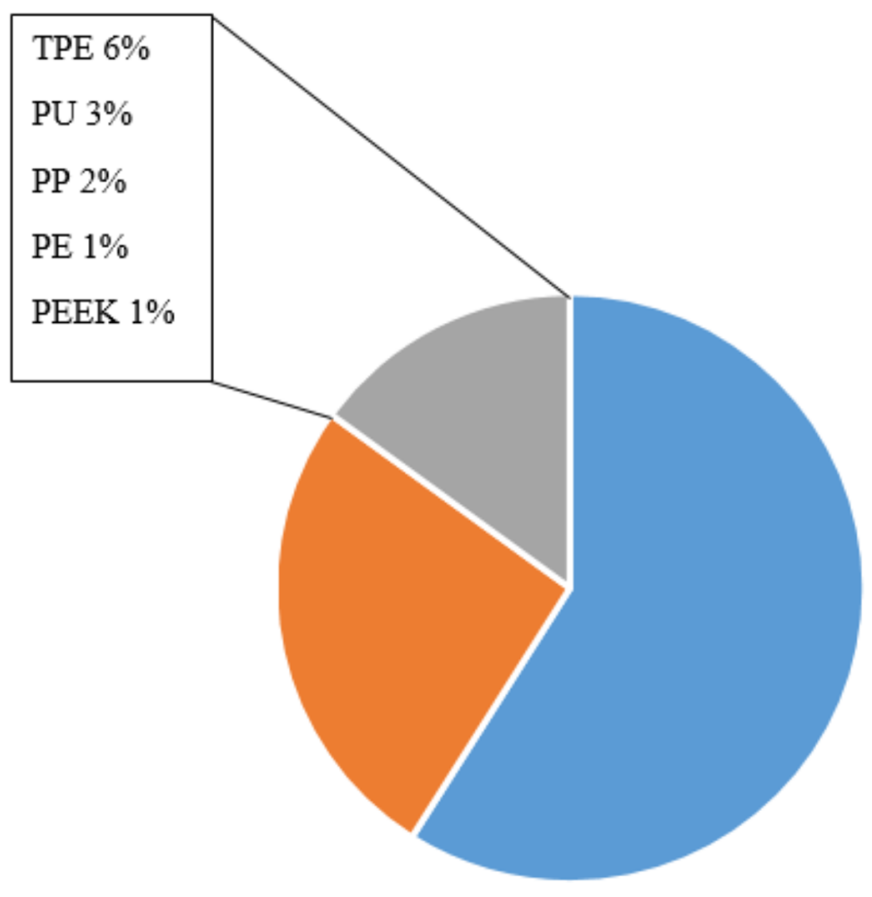

- $\mathrm{PA}-12$ - $\mathrm{PA}-11$ - Others

Fig. 1. Percentage distribution of polymers applicable to the PLS process [1].

In the recent past, considerable research efforts have been channelled towards the development of new powdered polymers with the aim of broadening the spectrum of PLS polymeric materials [5]. It is essential to characterize newly developed polymeric materials before processing them to determine their suitability which raises the need for wellestablished techniques for the characterization of powder. There is also a need to recycle the unsintered polymer powder because in PLS processing only about $5-20 \%$ of the supplied powder is utilized [6,7]. The remaining powder acts as the supporting structure for the printed components and general filling of the build platform. Furthermore, due to the limited choice of PLS polymers, the cost of the available polymeric materials is very high, thus further broaching the need to recycle the unused powder [8]. According to Mägi et al. [7], the cost of PA 12 is about $\$ 150$ per kilogram, while the cost of an equivalent polyamide feedstock for injection molding is about $\$ 3$ per kilogram. Therefore, it is critical to recycle the unused powder to reduce production costs.

The PLS technique results in the degradation of polymers due to exposure to high temperatures for extended periods of time $[7,9]$. It is imperative to investigate the degree of degradation of polymeric powder after each processing cycle to determine its viability for reuse. Powder characterization is required to ensure the building of products with known and repeatable properties [9] and it is important to have knowledge of the various methods of characterizing polymeric powders that are used in PLS. Some of these methods include differential scanning calorimetry (DSC), thermogravimetric analysis (TGA), laser diffraction analysis, gas pycnometry, scanning electron microscopy (SEM), and melt flow index (MFI) testing $[5,10]$. This paper presents a review of commonly used techniques for the characterization of polymeric powders that are used in the PLS.

\section{Overview of the PLS process for polymers}

Polymer laser sintering is one of the common types of AM technologies. This technology was invented by Carl Deckard and Joseph Beaman at the University of Texas, Austin [11]. The technology was commercialized by the DTM Corporation and EOS GmbH Electro Optical Systems in 1992 [11]. It involves the use of a laser beam to fuse powder particles together. The technique is applicable to a wide variety of materials ranging from metals, composites and ceramics to polymers [11]. Therefore, PLS is a widely applied AM technique.

The PLS technology is a matured prototyping as well as a manufacturing technique. A typical PLS machine is shown in Figure 2. Laser sintering of polymers comprises three steps, that is pre-heating, building, and cooling phases [3]. The pre-heating phases involve warming of the machine and polymeric powder (in the build chamber, as shown in Fig. 2) to temperatures just below the melting point of the material using a set of heaters placed around the build chamber. The building phase involves heating the polymeric powder using a laser beam to melt and fuse the particles following the geometry of a part to be printed. After each scanning cycle, the building platform is lowered by one-layer thickness and the process is repeated until the entire component is printed. The building phase is carried out at a constant temperature which is achieved by the set of heaters mentioned above. The third stage involves cooling and solidification of the printed components, the temperature of which is controlled through the use of another set of heaters placed along the sides of the extraction chamber, as shown in Figure 2. This is done by gradual cooling to prevent warping of the built parts. Nitrogen gas is also pumped into the built chamber during the three processes to reduce the degradation of the material as well as to minimize oxidation [12]. Laser sintering of polymers is a high-temperature process, the heating profile of which is summarized in Figure 3.

In Figure 3, the symbol $T_{s}$ is the starting temperature, $T_{B}$ the building temperature, $T_{\mathrm{E}}$ the extraction temperature, and $t_{B C}$ the combined building and cooling time. The combined building and cooling times are subject to the distribution, volume, and height of the parts being printed [3]. The curves in Figure 3 show that polymers are subjected to high temperatures during the entire PLS process. This exposure alters the properties of the polymers which influence the recyclability of the 


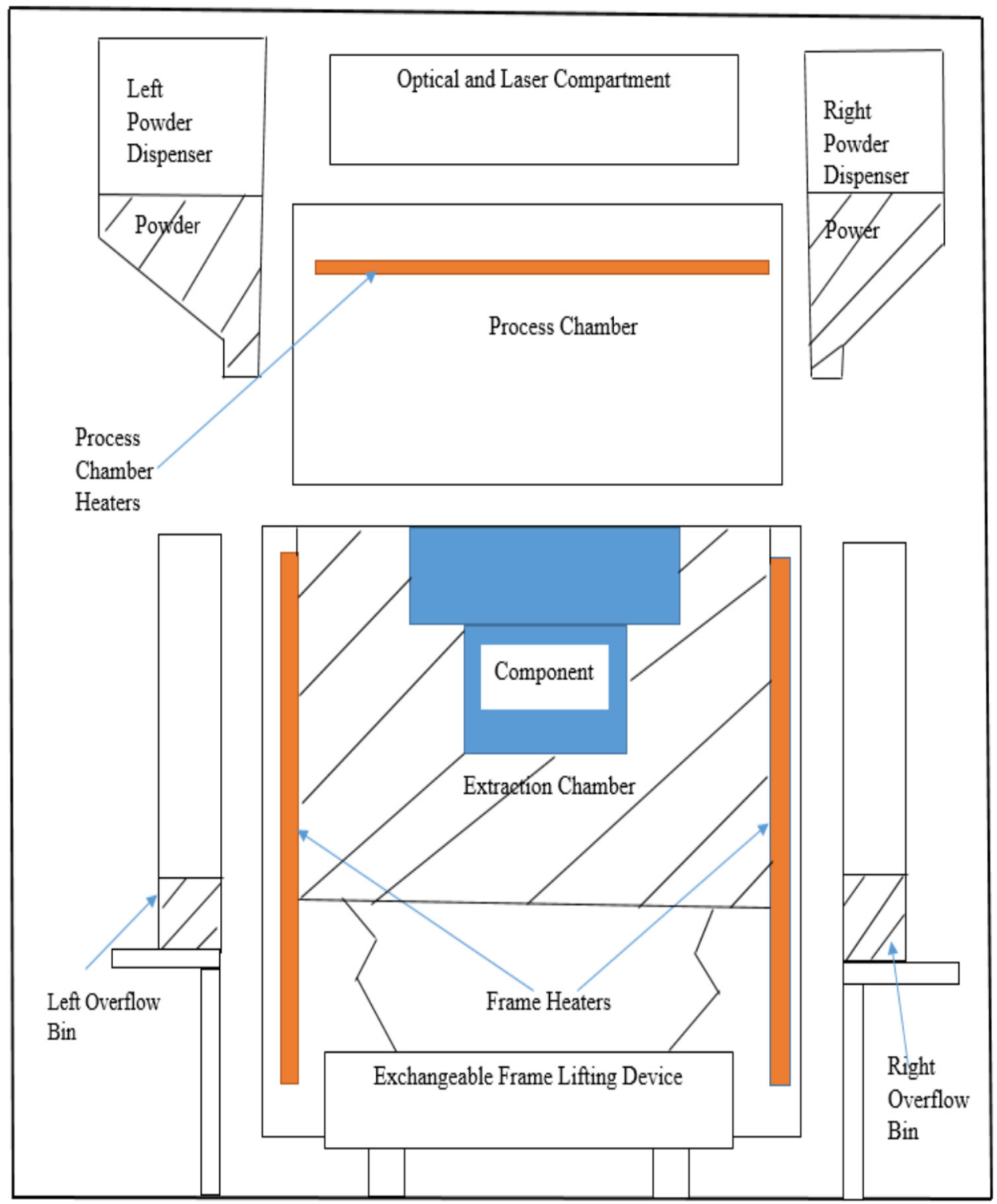

Fig. 2. A schematic representation of an PLS machine (EOSINT P380 Machine).

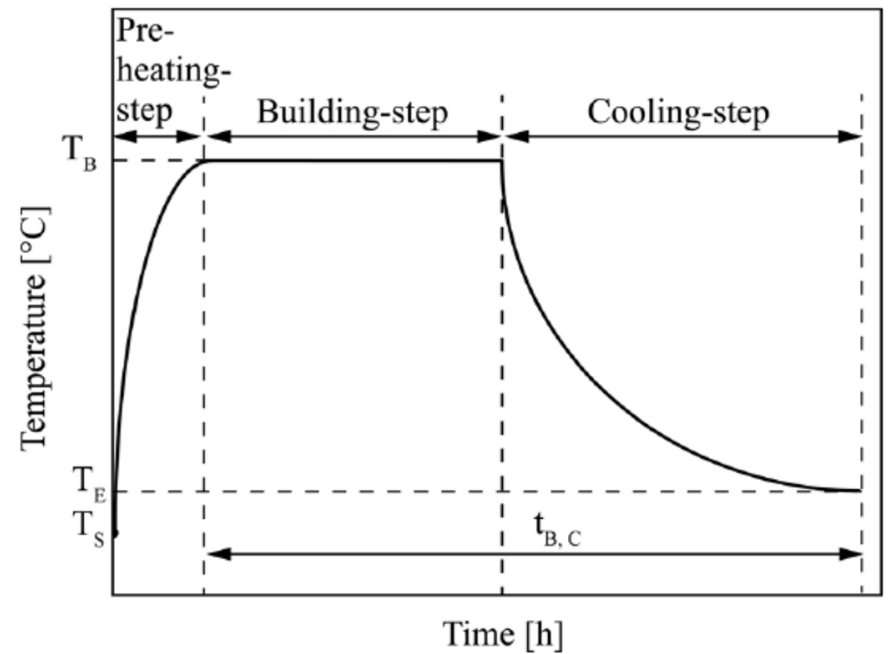

Fig. 3. The heating profile of polymeric material during PLS [3]. unsintered powder [13]. In addition, degraded powder compromises the quality and mechanical integrity of the printed parts $[14,15]$; hence, the need to characterize the used powder before re-using it to determine the degree of degradation.

\section{Properties of suitable polymers powders for use in PLS}

Polymers applicable to the PLS process should possess suitable intrinsic and extrinsic properties $[5,14]$. Extrinsic properties describe the physical characteristics of the polymers including powder density, particle size distribution and morphology. The intrinsic properties of the polymers consist of thermal, rheological and optical properties [16]. The thermal behaviour of polymeric 
powders includes melting point, sintering window, and temperature degradation point $[13,14]$. The rheological properties include the viscosity and surface tension of the material $[13,14]$. The optical characteristic determines the absorbing behaviour of laser energy $[13,14]$. The techniques for characterization of powder are based on the abovementioned intrinsic and extrinsic properties.

\subsection{Particle size distribution and morphology}

Particle size distribution and morphology need to be optimized for PLS powders. Suitable PLS polymeric powder particles should be near-spherical in shape to encourage as near free-flowing characteristics of the powders as possible [17]. Moreover, appropriate PLS polymer powders should have a powder distribution of between 20 and $80 \mu \mathrm{m}[17,18]$. Extremely small particles induce stickiness which reduces flowability [17]. Flowability of the powder determines uniform spreading of powder on the building bed. It is also crucial in PLS because it determines how layers are deposited across the build chamber. The layers should be uniform to ensure homogenous properties of the printed parts [19]. Lack of homogenous layers promote porous and weak components [20]. This may furthermore lead to distortion of the parts during laser sintering with the result that the recoater may catch on the parts and dislodge them from the powder bed. On the other hand, extremely large particles affect the spreading of the powder using a roller or blade. Large particles also discourage fusion which introduces porosity and in turn reduces the mechanical integrity of printed parts [21].

\subsection{Thermal properties}

Appropriate thermal properties are essential for the successful processing of semi-crystalline polymers using PLS. Polymers should have a high-temperature degradation point because PLS occurs under high temperatures [13]. The processing temperatures should be maintained between the melting point and the crystallization point of polymeric materials to prevent uneven solidification of the printed parts which might affect the geometrical accuracy as well as the surface finish of the manufactured components $[8,13]$. The difference between the melting point and the crystallization point of a polymeric material is referred to as the sintering window [8,13]. Suitable polymers are characterized by a wide and sufficient sintering window which prevents crystallization of the polymers during processing $[8,13]$. Rapid crystallization of the printed components is a major hurdle in PLS because it encourages curling, which in turn affects the surface finish and dimensional accuracy of the produced parts [17]. Furthermore, suitable polymers should have a narrow melting point range to prevent the use of high laser energy when fusing the powder particles [8]. High laser energy leads to greater degradation of the powder supporting the components being printed which hampers the recyclability of the material [13]. Therefore, thermal properties do significantly determine acceptable polymers for the PLS process.

\subsection{Rheological properties}

Viscosity and surface tension also determine the applicability of polymers in the PLS process. A suitable polymeric material should have low viscosity and low surface tension to ensure adequate coalescence of the powder particles $[17,22,23]$. Unlike injection molding, PLS does not provide additional compacting; therefore, it is important that the material has low melt viscosity with zero shear stress [17]. Low surface tension encourages better flowability of the material. It should be noted that extremely low melt viscosity compromises the surface roughness of the printed components because the melt seeps into the surrounding support powder [8]. Viscosity, surface tension and shear stress thus form crucial material-property requirements for PLS polymers.

\subsection{Optical properties}

Optical properties influence the PLS process. A suitable polymeric material should be able to absorb sufficient laser energy to ensure satisfactory fusion of the powder particles. Most of the polymers sufficiently absorb laser energy of the commonly utilized $\mathrm{CO}_{2}$ laser with a wavelength of about $10 \mu \mathrm{m}$ [17]. The optical characteristics of most polymers are sufficient for PLS processing; therefore, they do not significantly affect PLS processing of polymers.

\section{Findings and discussion: various techniques commonly used to characterize polymer powders used in PLS}

There are various techniques for the characterization of polymers powders for PLS. These techniques are classified according to whether they address the intrinsic or extrinsic properties of powder. The ensuing discussion provides details of the commonly utilized strategies for the characterization of powder in these two categories. 


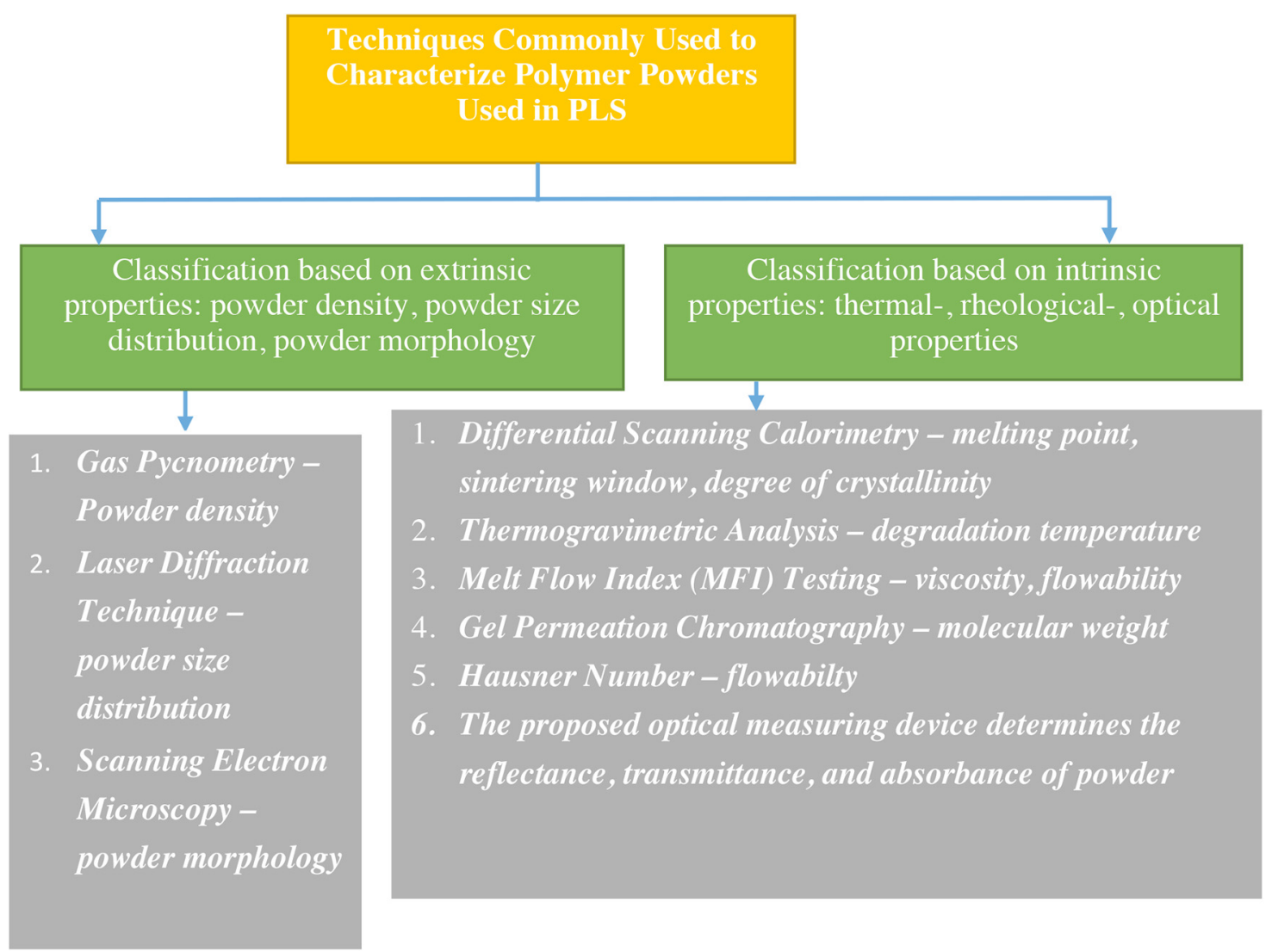

\subsection{Determination of powder density using gas pycnometry}

Powder density is commonly determined using a gas pycnometry technique. A gas pycnometer is a device that uses a gas, such as nitrogen or helium, to determine the density of a particular material [24]. Helium gas is commonly utilized because it exhibits ideal gas characteristics. Various types of gas pycnometers include constantvolume pycnometers, variable-volume pycnometers, and comparative pycnometers [25]. The general procedure for using the equipment involves first weighing a sample of polymer powder. The sample is then placed into a pycnometry container of known volume. Helium is utilized to displace the air. The volume of helium used is obtained using the ideal gas law. Subtracting this volume from the volume of the container yields the volume of the particles of powder. The density of the powder is then determined using the following expression:

$$
\text { Density }=\frac{\mathrm{kg}}{\mathrm{m}^{3}}=\frac{\operatorname{Mass}(\mathrm{kg})}{\operatorname{volume}\left(\mathrm{m}^{3}\right)}
$$

The gas pycnometry technique is associated with the advantages of ease of use, the machine can be left unattended after loading, guaranteed reproducibility and pycnometers are pre-calibrated and are therefore ready for use. However, the method is limited by operator-dependent reading which reduces accuracy.

\subsection{Laser diffraction technique}

The laser diffraction technique is employed in determining the distribution of powder particles using diffraction of a laser beam. During the process, a laser beam is allowed to pass in between particles and the angular distribution of scattered light is analyzed [17]. When the particles are suspended in a liquid, the process is referred to as wet laser diffraction, whereas when the particles are suspended in the air, the technique is termed as dry laser diffraction [17]. The technique makes use of the Fraunhofer and Mie theories. The Fraunhofer theory assumes that all the particles are much larger than the wavelength of the laser beam used. The particles should be at least 40 times the wavelength of the laser beam [26]. Hence, only scattering at the contour of the particles is considered. The Mie theory is used when the particles are much smaller than 40 times the wavelength of the laser beam [26]. The advantages of the laser diffraction technique include small quantities of samples required, short time of analysis, reliability, and reproducibility. However, high cost of instrumentation limits the use of the laser diffraction technique for characterization of powder [27].

\subsection{Scanning electron microscopy}

The Scanning Electron Microscope (SEM) technique can be used to determine the morphology of powder particles. A schematic representation of a SEM complete with its 
accessories is shown in Figure 4. The SEM operates by focusing a beam of electrons from an electron gun at a test specimen using a system of electromagnetic lenses [28]. Once the beam of electrons hits the specimen the secondary electrons, backscattered electrons, transmitted electrons or the current generated in the specimen are used to provide signals for SEM observations [29]. The magnification of a SEM is a function of the amount of current supplied [29].

Before testing, polymeric powders should be dried well. The powder is then plated with gold or platinum to reduce surface charging [29]. After this, the powder is mounted firmly inside the SEM and then tested, adhering to standard testing parameters (especially the accelerating voltage). An accelerating voltage of $25 \mathrm{kV}$ is recommended

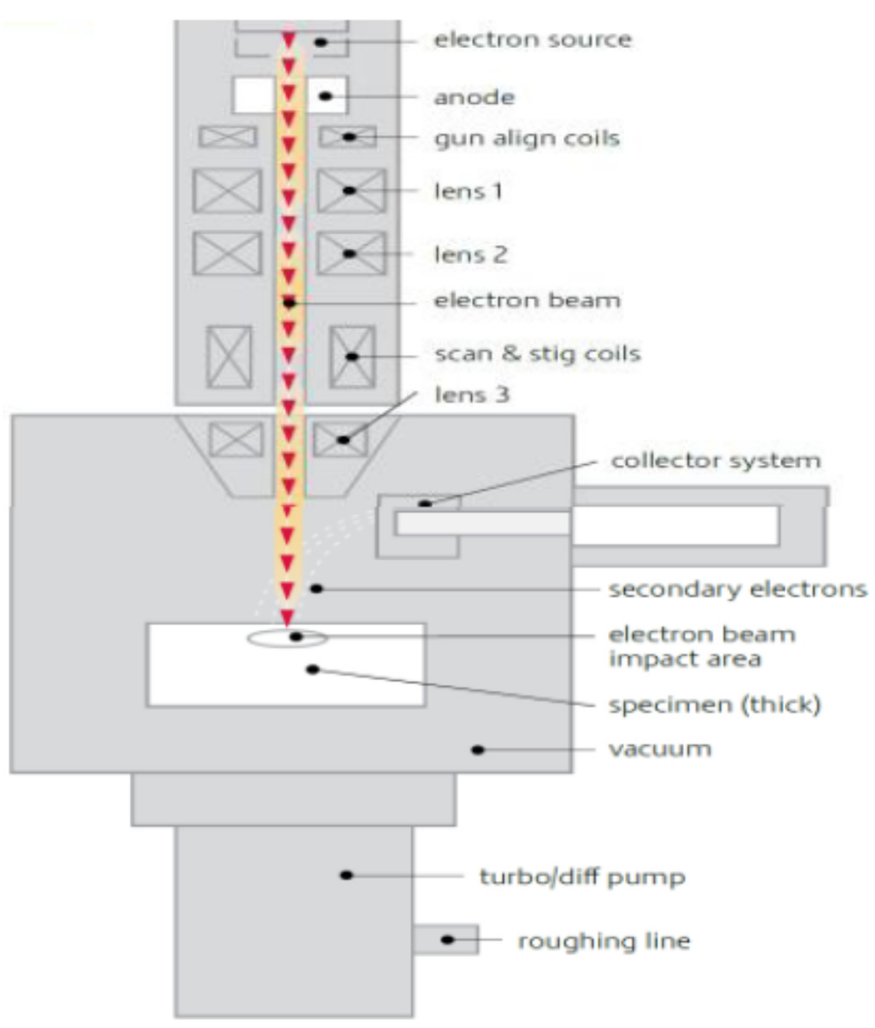

Fig. 4. Schematic diagram of an SEM [28]. for PLS polymeric materials [30]. Figure 5 shows an example of powder morphology obtained using SEM. The experiment giving rise to the micrographs was conducted by Berretta et al. [30] to determine the morphology of PA2200 powder.

The SEM technique offers various advantages: for example, it is easy to operate the equipment. In addition to this, SEM provides detailed images with versatile information [31]. It is also fast, taking less than five minutes to obtain results. The limitations of SEM include the size of sample scanned and cost of the equipment. The SEM also requires a large space. Besides, the preparation of specimens is time-consuming and special training is required to operate the equipment.

\subsection{Differential scanning calorimetry}

Differential Scanning Calorimetry (DSC) is a thermoanalytical strategy that is utilized when investigating the thermal properties of polymers. The technique is used to differentiate between appropriate and less suitable powders for use in PLS. The set-up of the DSC process is as shown in Figure 6.

During the DSC process, the samples of known mass are heated and cooled and the alterations in heat capacity of a particular material with respect to changes of heat flow are monitored. A typical DSC thermogram is represented in Figure 7.

The following parameters are obtained from a DSC test: onset of melting $\left(T_{m}\right)$ and crystallization $\left(T_{c}\right)$ points, peak melting and crystallization points, sintering window $\left(T_{m}-T_{c}\right)$, and degree of crystallization represented by the symbol $(C \%)$ defined as $\left(\Delta H_{m} / \Delta H_{m}^{0}\right) \times 100 \%$ [13], where the symbol $\Delta \mathrm{H}_{m}$ stands for experimental melting enthalpy and $\Delta \mathrm{H}_{m}^{0}$ stands for theoretical melting enthalpy of the material. The DSC is the second-most-used technique for characterization of PLS polymeric materials. The method is popular due to the short sample throughput, elaborate thermal properties and the small size of samples required. DSC is limited in that it is dependent on the skill of the operator. The technology is also very sensitive to changes, such as external temperature, which reduces the accuracy of the results obtained.
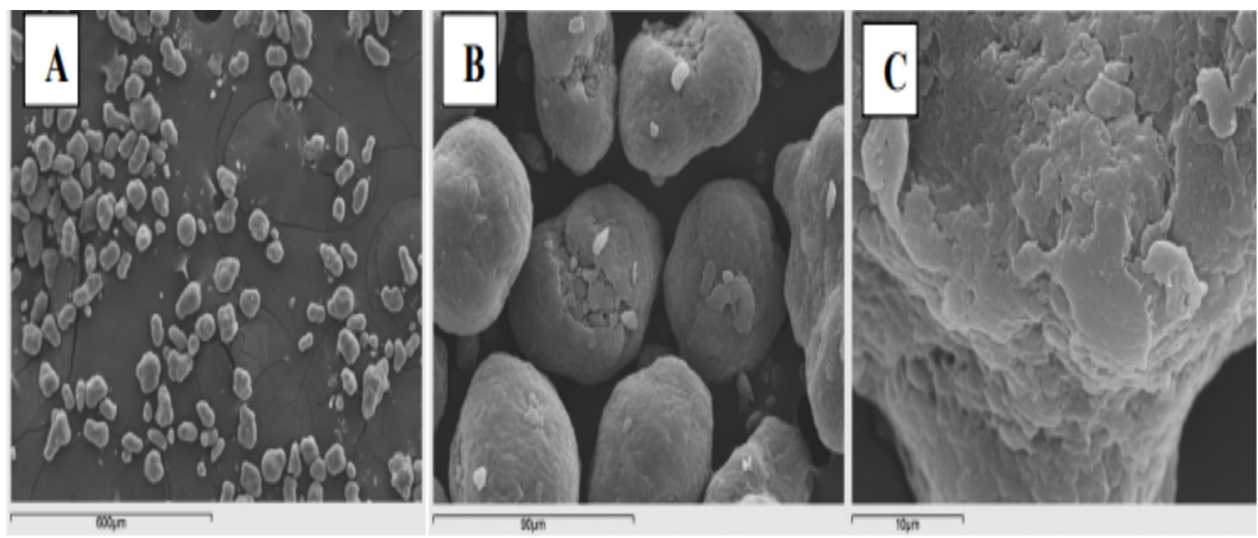

Fig. 5. Powder morphology for virgin PA2200 using low (A), medium (B), and high magnifications (C) [30]. 


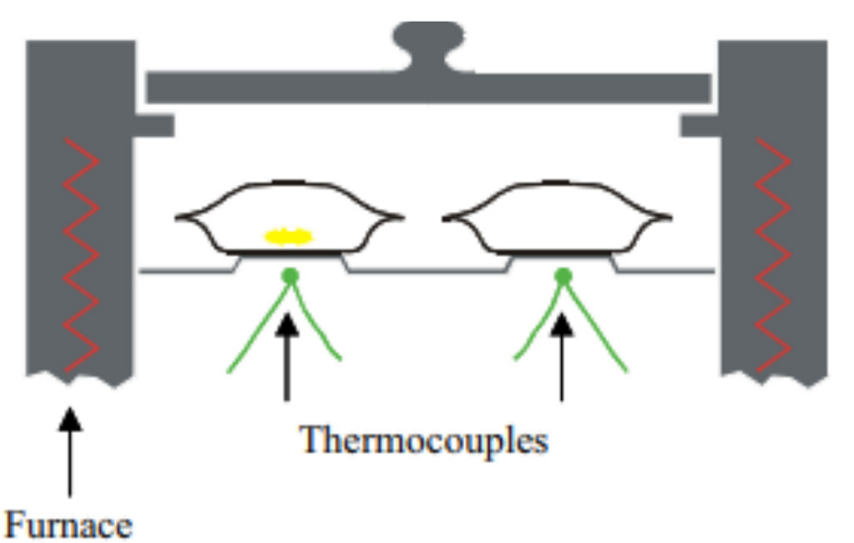

Fig. 6. A DSC experimental set-up [32].

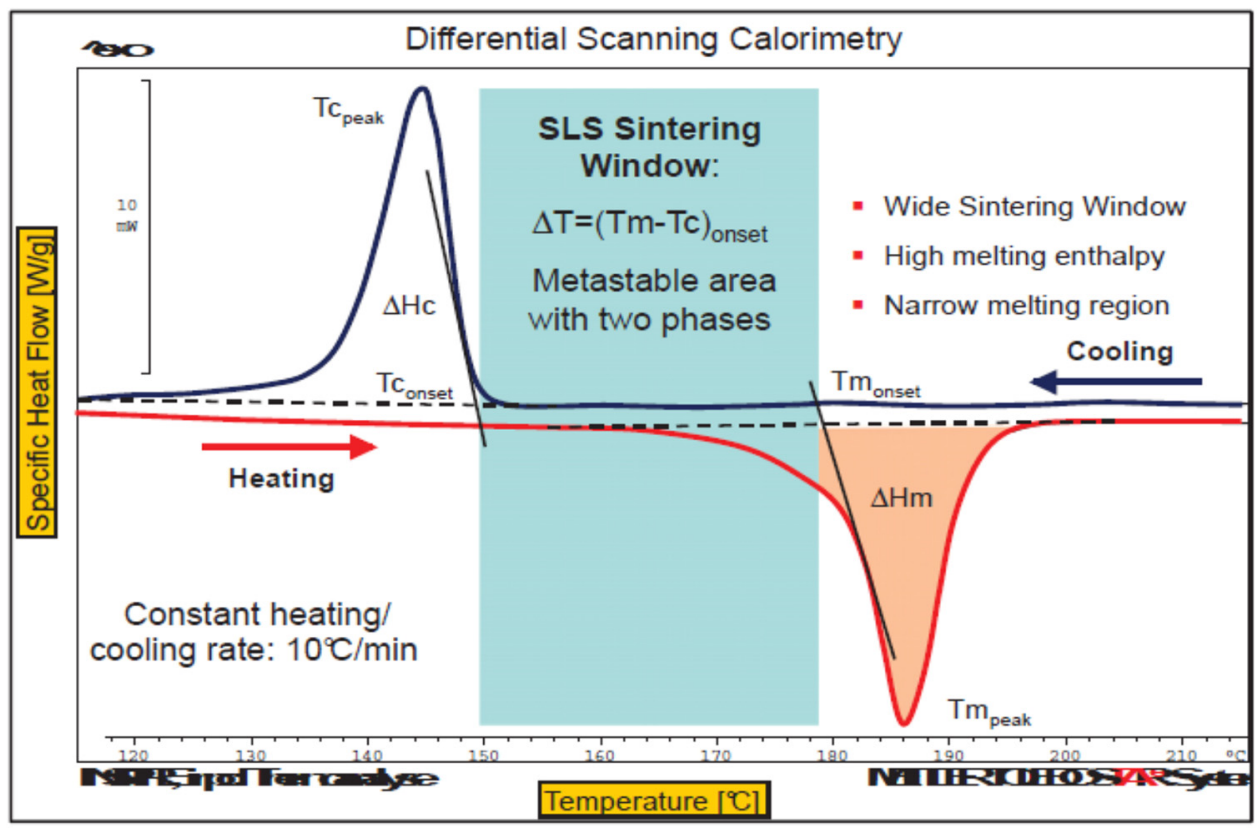

Fig. 7. Typical example of a DSC thermogram [17].

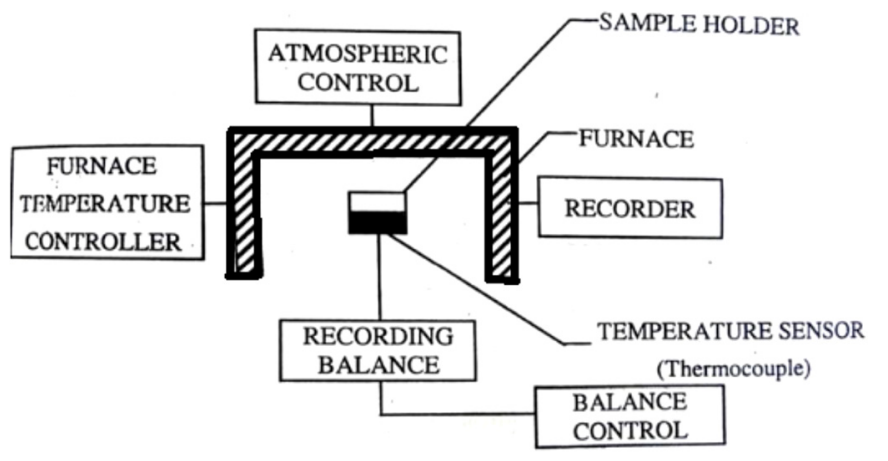

Fig. 8. Typical experimental set-up for thermogravimetric analysis [33]. 


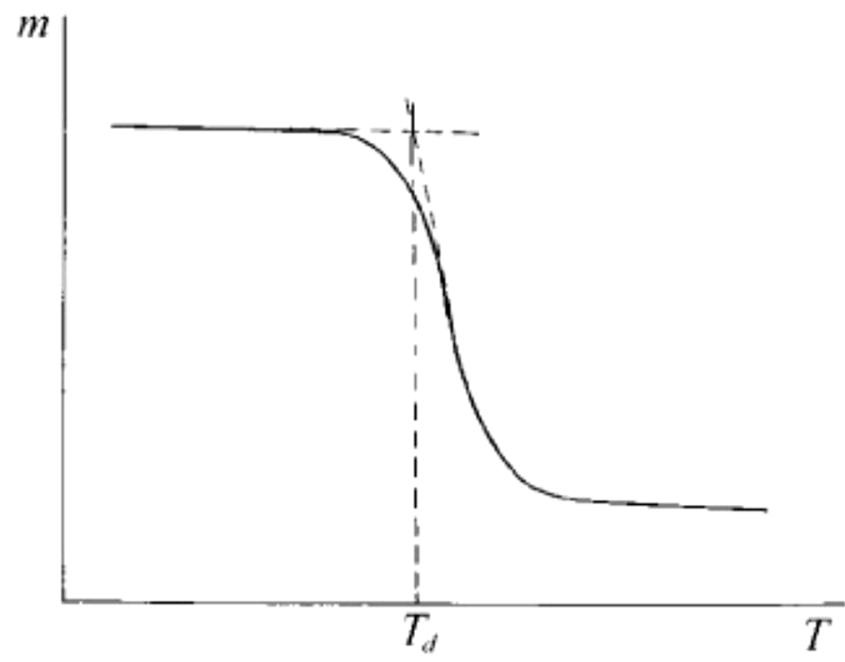

Fig. 9. An example of TGA thermal curve [34].

\subsection{Thermogravimetric analysis}

Thermo gravimetric analysis (TGA) is a technique utilized to establish the degradation of a substance by monitoring the mass of the substance as a subject of temperature or time [33]. The apparatus consists of a pan, precision balance, temperature programmer, recorder and a furnace, as shown in Figure 8. During the experiment, the mass of a sample is monitored when heating or cooling. The exercise should be conducted in the presence of an inert gas such as helium or neon.

A typical TGA thermal curve is shown in Figure 9, from which the temperature at which the polymer degrades $(\mathrm{Td})$ can be determined. The temperature of degradation is the point at which the curve of mass against temperature changes abruptly at the point of the intersection of the upper horizontal curve and the tangent of the sigmodal curve running through its point of inflexion.

The TGA technique requires small sample quantities with minimal preparation. The method is also highly accurate. However, it is not easy to interpret the data obtained.

\subsection{Melt flow index (MFI) testing}

The melt flow index testing is conducted using an MFI tester for purposes of determining the ease of flow of a material. For polymers such as polyamide 12 and polypropylene, the tester consists of a $2.16 \mathrm{~kg}$ test load, charging rod, cleaning rod, tungsten carbide die with a capillary diameter of $2.095 \mathrm{~mm}$, and a die ejector [35], as shown in Figure 10.

The testing process begins by cleaning the barrel and die using the cleaning tool and special cleaning paper. After cleaning, about six grams of the powder sample is loaded into the barrel. The piston with a mounted test load is inserted into the barrel and the powder in the barrel is preheated for about six minutes to different temperatures for different polymers; for instance, $230^{\circ} \mathrm{C}$ for polypropylene and $2355^{\circ} \mathrm{C}$ for polyamide 12 [35]. The time taken by the

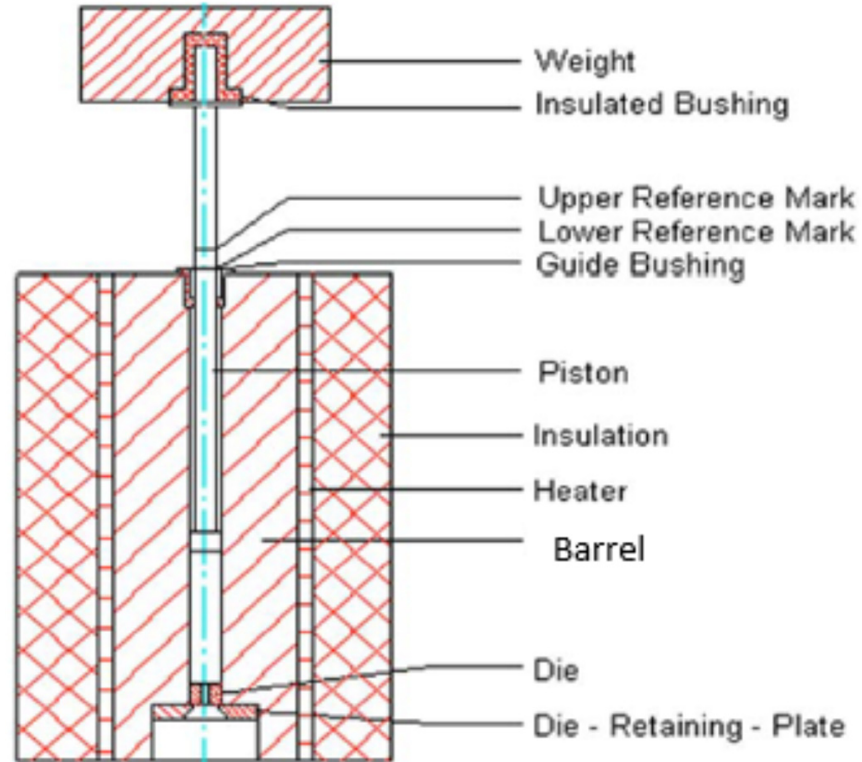

Fig. 10. A typical arrangement of an extrusion plastometer [35].

piston to move between two marked points is measured. The mass of the ejected polymer material is determined using an electronic weighing machine and the value of MFI calculated using Equation (2). The MFI value of virgin PA12 is about $45-50 \mathrm{~g} / 10 \mathrm{~min}$ and it degrades from this range with repeated use [36]. After the value reduces below $18 \mathrm{~g} / 10 \mathrm{~min}$, the powder is discarded, which happens after the 7th or 8th re-use cycle [37]. The cut-off points for other materials, such as PP, have not been determined experimentally. The MFI is the most commonly utilized characterization technique for PLS polymeric materials because it is easy to use, inexpensive, does not require specialized training and yields rheological properties of polymeric material which determines the suitability of the polymer being tested. However, it has limited accuracy and reproducibility.

$$
\text { MFI }=\frac{600 \times \text { Mass of polymer extruded }}{\text { Time taken to extrude the polymer }}
$$

\subsection{Gel permeation chromatography}

Gel Permeation Chromatography (GPC) technology is used to determine the molecular weight of the powders. The method is a type of size exclusion chromatography technique (SEC) and involves separating the powder particles from the largest to the smallest [38]. The technique involves determining the molecular weight of the polymer based on retention time for penetration into a porous material. During testing, the samples are dissolved in a solvent such as 1,1,1,3,3,3-hexafluoro-2-propanol' (HFIP) $(99.5 \%)$ and stirred for $24 \mathrm{~h}$ [38]. After this the samples are allowed to settle for $12 \mathrm{~h}$. The samples must be filtered prior to the experiment. The injection volume should then be set as $20 \mu \mathrm{l}$ and the flow rate as $0.700 \mathrm{ml} / \mathrm{min}$. The GPC technique requires a short time for the preparation 
of samples. In addition, the actual measurements are simple, quick and reproducible. However, it is subject to inaccuracy.

\subsection{The zero-shear test}

The zero-shear test is performed on a rotational rheometer such as the one shown in Figure 11. Measurements are usually conducted between shear rates of 0.005 and $0.01 \mathrm{~s}^{-1}$ [39]. In zero-shear tests, powder tablets are commonly used to facilitate loading. These tablets are prepared using a plate press at a temperature and pressure of 80 bar and 100 bar, respectively [39].

The rotational rheometer is easy, fast and inexpensive to operate. Furthermore, small sample sizes are required. However, it does not yield sufficient data to accurately characterize polymeric materials.

\subsection{Determining the flowability of powder material using the Hausner number}

Hausner ratio is a dimensionless number which is a quotient between the tapped density of a material and its

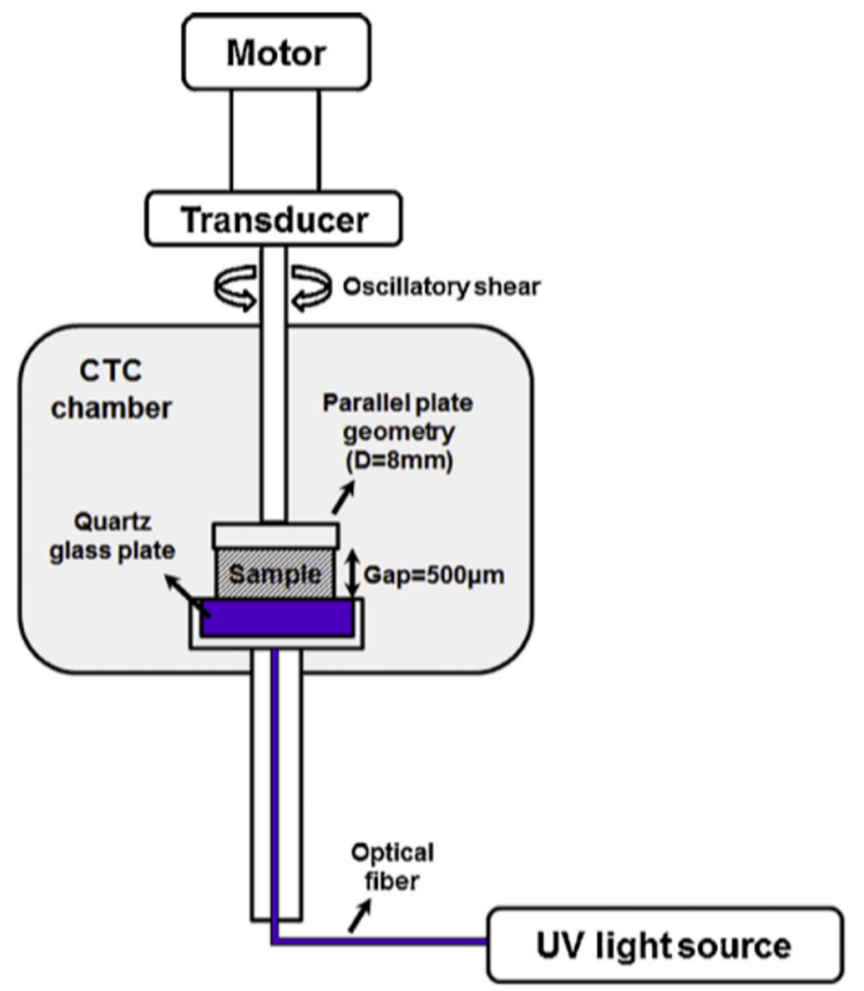

Fig. 11. Schematic representation of a rotational rheometer [40]. bulk density [41]. Bulk density is the ratio of the mass of a polymeric material to the volume occupied by the material [41]. This value can be obtained using a bulk density tester. Tapped density is obtained by filling a specific measuring cylinder with polymeric powder material and then compacting the powder by knocking the cylinder on a board at a particular frequency [24]. The Hausner ratio determines the flowability of a material. The ratio is inversely proportional to the flowability of a material. Polymers with a Hausner number less than 1.25 show freeflowing behaviour, while polymers with a Hausner number greater than 1.4 have flowability problems [13,18]. The best flowability is obtained when the Hausner ratio is equal to one [13]. The Hausner number is obtained using Equation (3).

$$
\text { Hausner Number }=\frac{\text { Tapped Density }}{\text { Bulk Density }}
$$

Hausner number testing is simple, inexpensive and does not require specialized testing. The technique is susceptible to inaccuracies and it does not yield sufficient data.

Flowability of powder can also be measured using other different techniques. Schmid et al. [42] summarized some of these methods as illustrated in Table 1.

The methods are easy to use and can substitute the MFI testing, which focuses only on the viscosity of melt material as opposed to the powder flowability.

\subsection{Measuring the optical properties of PLS polymeric materials}

The optical properties of polymers influence the rate at which they absorb laser energy. A suitable material should take sufficient laser energy to ensure satisfactory coalescence of the powder particles to prevent porosity which affects mechanical strengths of printed parts. Studies show that most polymers absorb sufficient laser energy at a wavelength of around $10 \mu \mathrm{m}[17,19]$.The method used by Laumer et al. [43] to determine the optical properties of polymeric powders uses two spheres (Fig. 12). The set-up measures reflectance, transmittance, and absorbance of the powder material. The process commences by depositing a polymer material in a specimen holder which is positioned between the spheres. A potassium chloride specimen holder is used when using a $\mathrm{CO}_{2}$ laser beam (wavelength, $10.6 \mu \mathrm{m}$ ), while a soda-lime glass holder is utilized for a thulium fibre laser beam (wavelength, $1.94 \mu \mathrm{m})$. After setting up the apparatus, the laser beam propagates through the samples at an inclination of $8^{\circ}$ from

Table 1. Common techniques for determining powder flowability [42].

\begin{tabular}{ll}
\hline Method & Parameter being measured \\
\hline Bed expansion ratio & Determines fluidized height against upstream fluid flow \\
Angle of repose (DIN ISO 4324) & Determines the pile angle \\
Ring shear cell (ASTM D 6773) & Determines shear force against normal pressure or compression rate \\
Revolution powder analyzer & Determines the avalanche angle \\
\hline
\end{tabular}




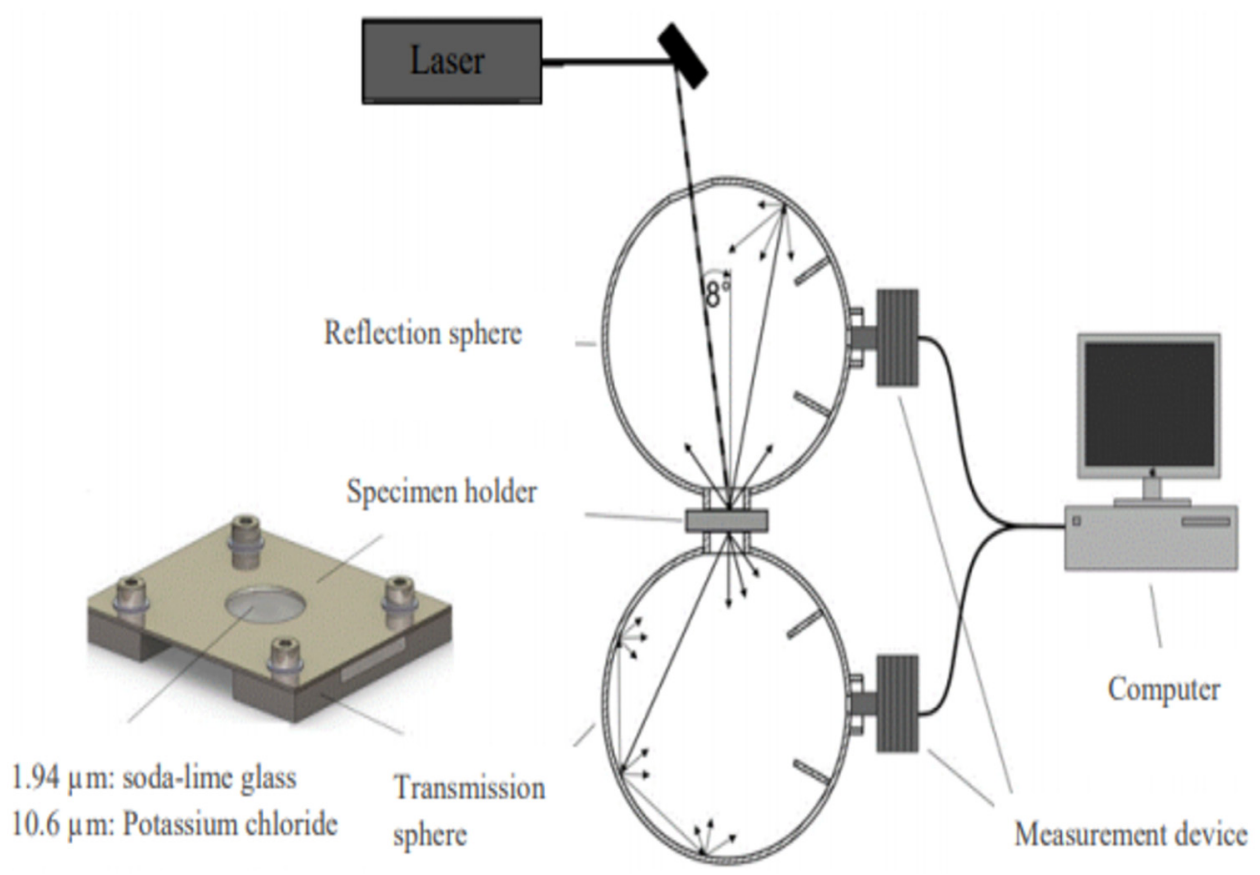

Fig. 12. Set-up for measuring optical properties of PLS polymeric materials [43].

the upper sphere (see Fig. 12). The inclination prevents direct reflection of the beam through the opening of the upper sphere. At contact, the powder reflects the beam and the reflected power is measured by two heads on the spheres. The powder also absorbs and transmits the beam. The transmitted beam is measured in the same way as the reflected beam. After this, the absorbed beam is then calculated using computer software on the basis that the total power $=$ reflected power + transmitted power + absorbed power. The optical characteristics of polymers are seldom investigated because most polymers absorb sufficient laser energy for PLS processing.

It is evident that the amount of energy absorbed by polymeric materials is subject to the reflection, transmission, and absorption properties. Hence, energy absorption capacity of materials might be influenced by their color. Translucent materials are expected to absorb laser energy more compared to white powder because of reduced reflection and transmission, which promotes energy absorption. Ligon et al. [44] proposes addition of graphite or carbon black if the absorption of a polymer is not sufficient.

\section{Up-to-date investigations on the comparisons of properties between virgin and aged powder}

As has been noted in this paper, PLS is a high-temperature process which degrades the properties of polymer feedstock materials, and thus affects recyclability. The material properties of the feedstock that are most altered by the high-temperature processes include particle size and distribution, rheological characteristics and thermal
Table 2. Results from a laser diffraction test for PA [39].

\begin{tabular}{lll}
\hline Powder & $\begin{array}{l}\text { Powder particle } \\
\text { distribution }(\mu \mathrm{m})\end{array}$ & $\begin{array}{l}\text { Mean powder } \\
\text { particle size }(\mu \mathrm{m})\end{array}$ \\
\hline Fresh PA 12 & $30-150$ & 80 \\
Mixed PA 12 & $30-150$ & 75 \\
Aged PA 12 & $30-150$ & 80 \\
\hline
\end{tabular}

behaviour. The mechanical properties of the printed components are also impacted by the re-use of the powder. The ensuing discussion investigates the influence of re-use of common polymeric materials in the PLS process. PA12 accounts for $95 \%$ of all polymeric powders used in PLS, thus the preponderance reference to it here $[5,8]$.

\subsection{Effects of PLS re-use cycles on polymeric powder particle size and distribution}

Dadbakhsh et al. [39] investigated the effects of PA 12 powder re-use on the properties of the powder. The authors considered virgin, aged, and aged-virgin mixture powder batches. A Malvern Master sizer Microplus that uses laser diffraction technology was employed to measure particle size distribution (PSD). It was established that the size of powder for the three batches remained around 55-60 $\mu \mathrm{m}$, as illustrated in Figure 13. A summary of the particle sizes of the three batches of powder is shown in Table 2 .

In another study, Ghita et al. [45] found that the mean size of polyether ketone (PEK) powder particles increased marginally when subjected to a high laser sintering process. Moreover, the particle size distribution was observed to widen after aging (Fig. 14). The authors noted that deviation from the optimal powder size introduces 
Table 3. Particle size distribution for Laser PP CP 60 after print cycle [46].

\begin{tabular}{lll}
\hline Power batch & Particle size distribution $(\mu \mathrm{m})$ & Mean particle size $(\mu \mathrm{m})$ \\
\hline Virgin material & $25.0-120$ & 63.7 \\
Aged powder (after one print) & $19.0-105$ & 65.7 \\
Mixed powder & $26.2-115.5$ & 64.0 \\
\hline
\end{tabular}

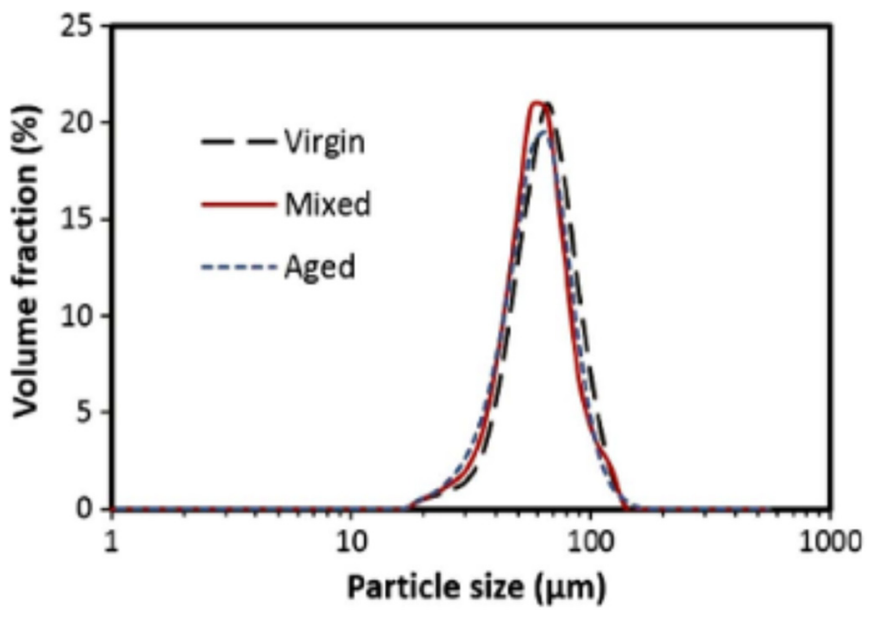

Fig. 13. Typical results obtained from the laser diffraction of polyamide 12 [39].

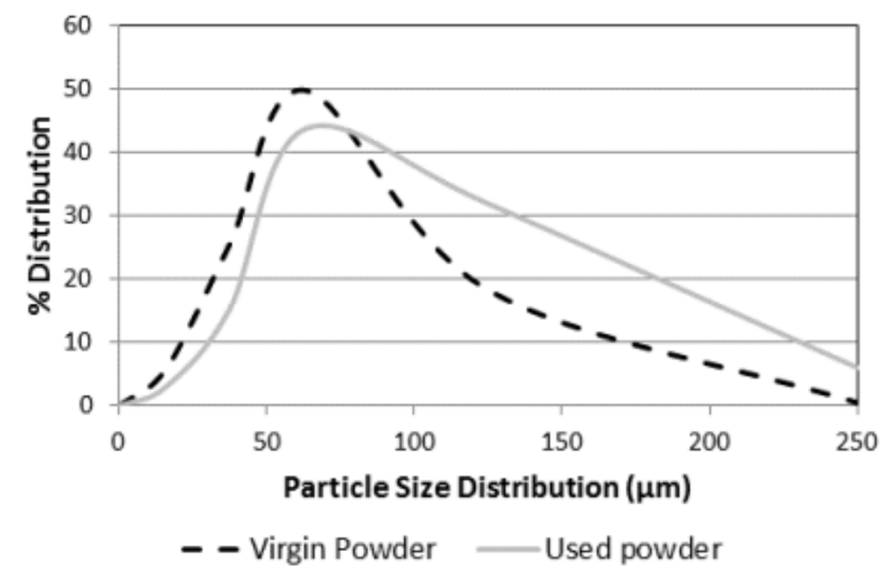

Fig. 14. Powder particle distribution for virgin and used HP3 PEK material [45].

difficulties in processing due to problems of flowability of particles that were too small. Although flowability is subject to the properties of particles, such as size and morphology, it is also influenced by the environmental factors (humidity and temperature) $[19,20]$. Hence, PLS powders should be stored in a dry environment to prevent absorption of moisture, which in turn would affect the flowability and processability of the materials.

Research by Mwania et al. [46] on Laser PP CP 60, a polypropylene material from Diamond Plastics, GmbH, showed similar characteristics. In this work, the average

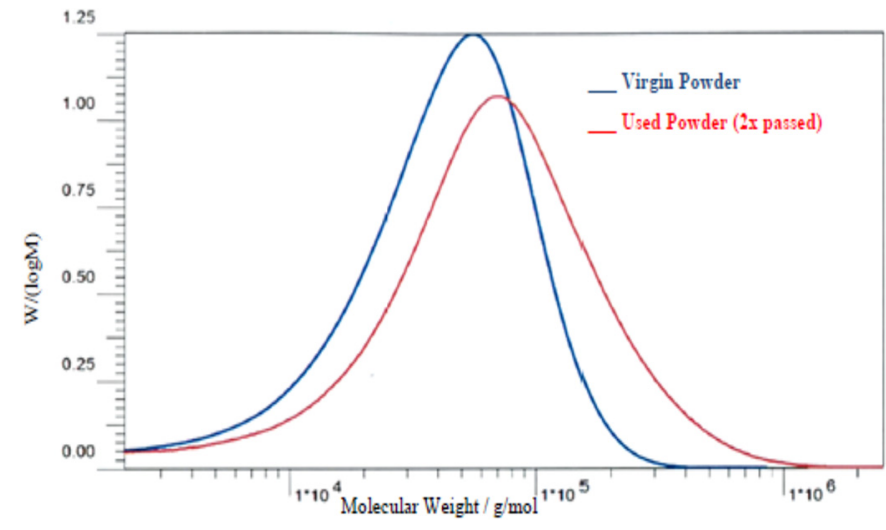

Fig. 15. The relationship between molecular weight of polyamide 12 and ageing [47].

powder particle size was seen to increases lightly after a single print cycle, as illustrated in Table 3.

\subsection{Effects of PLS re-use cycles on rheological properties of polymeric powder}

Dadbakhsh et al. [39] also found that molecular weight of powder increases with aging which is attributed to crosslinking of the long carbon chains. The authors measured the molecular weight of the powder using gel permeation chromatography. This claim is consistent with the findings of Rüsenberg et al. [47], as illustrated in Figure 15. The graphs in Figure 15 show that the used powder (red curve) has a higher molecular weight than the virgin material (blue curve).

It is expected that the viscosity of the PLS polymeric material should rise with increasing molecular weight after each re-use cycle. These expectations were confirmed by Gornet et al. [48], who measured the flow characteristics of PA 12 powder from 3D Systems Corporation using an extrusion plastometer. It was found in this work that the melt flow rate of the powder decreased with each build cycle, as shown in Figure 16.

Kuehnlein et al. [49] also established that the viscosity of PA 12 increases with processing time. The authors found that the melt flow rate of the material reduced from $28 \mathrm{~cm}^{3} / 10 \mathrm{~min}$ to $7 \mathrm{~cm}^{3} / 10$ min after four hours of oven storage at $170{ }^{\circ} \mathrm{C}$. Moreover, another study by Aldahsh [50] established that the viscosity of a cement/PA 12 composite increased with processing time and temperature. Wegner and Ünlü [51] showed that PP powder experiences minimum deterioration of rheological properties. They 


\section{Melt Index Change over 7 Builds}

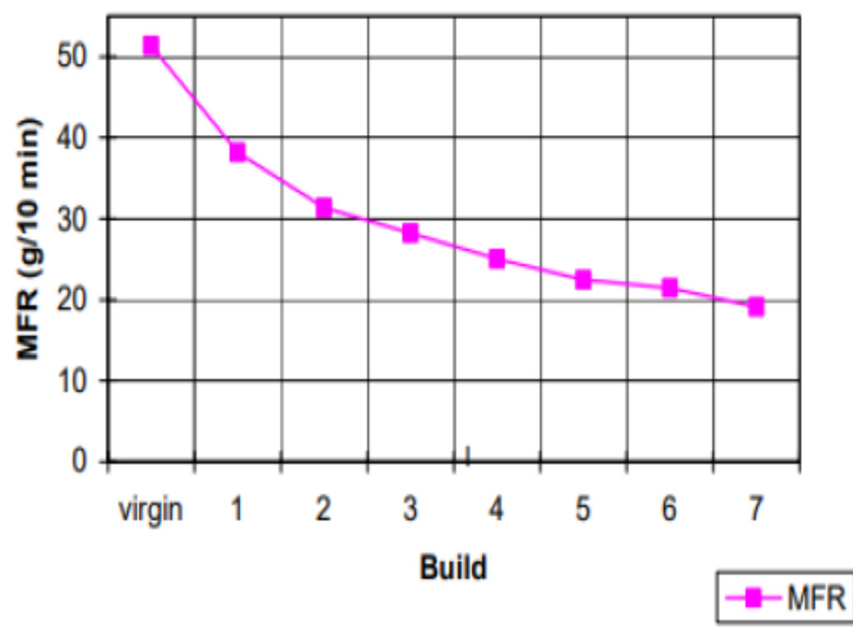

Fig. 16. The trend of melt flow rate of PA 12 powder with re-use cycles [48].

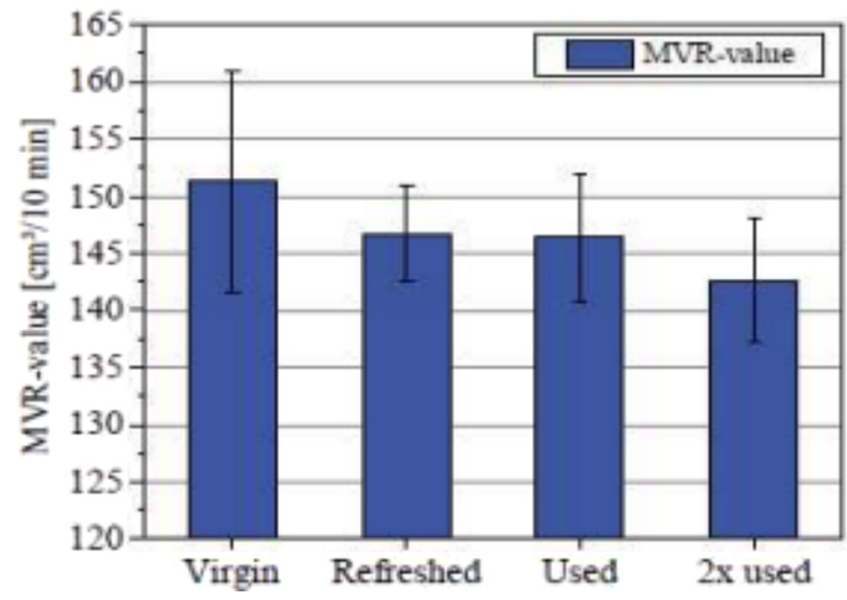

Fig. 17. The trend of melt flow rate of PP powder with re-use cycles [51].

found that the MFI of PP material decreases only by $3 \%$ when the powder is re-used in the PLS process [51]. Figure 17 shows the trend of MFI changes of PP after two re-use cycles.

Increased viscosity also affects the properties of the printed parts. For PA 12 powder material, an "orange peel" surface texture is formed that adversely impacts the geometrical, dimensional accuracy and surface roughness of built components [39]. This demands that used PA 12 be mixed with virgin material after every cycle to prevent formation of the "orange peel". The mixing ratio is proposed by the manufacturers, EOS GmbH Electro Optical Systems and 3D Systems Corporation, as 70:30 and 50:50 for aged to virgin powder ratio, respectively. EOS GmbH Electro Optical Systems manufactures PA 2200, while 3D Systems Corporation produces Duraform, PA 12 polymeric powder grades. The phenomenon of the forma- tion of "orange peel" in other polymers, such as PP, due to re-use has not been examined extensively, but is attributed to increasing viscosity of the materials arising from increasing molecular weight. Hence, there is need for further investigation on the effects of PLS re-use cycles on the properties of polymeric powder materials.

Apart from viscosity, molecular weight of the materials affects the degree of crystallinity of the powder as well. Dadbakhsh et al. [39] determined that the crystallinity of PA 12 powder increases with aging to a maximum point after which it starts to decrease. The phenomenon can be attributed to the crystal growth during the PLS process which results in increased crystallinity. However, after the powder is melted, the higher molecular weight and long carbon chains prevent ordered chain folding resulting in reduced crystallinity. Increase in crystallinity increases the ultimate tensile strength of printed parts at the expense of percentage of elongation to break which decreases [8]. Besides, increased crystallinity increases curling and shrinkage rate of printed parts which affects the printing process of polymeric materials [8]. For a successful PLS process, the material should exhibit minimal curling to ensure free movement of the recoater, as the PLS process is terminated when the recoater picks up parts from the laser bed due to effects of curling.

Another study by Schmid et al. [42] analyzed the flowability of aged Duraform DF using Hausner Ratio. The authors used the round Robin test (DIN 38402-45), where it was established that the Hausner number of the powder increased from 1.148 to 1.225 after a single print cycle. The results indicate that the flowability of the materials decreases with printing cycles, which will impede recyclability. Suitable PLS materials should have a Hausner ratio less than 1.25. Polymeric powders with values greater than 1.4 are considered cohesive, and difficult to print.

\subsection{Effects of re-use PLS cycles on thermal properties of polymeric powder}

The melting points of polymeric materials are also affected by the re-use of powder. Gornet et al. [48] utilized DSC to investigate the influence of re-using PA 12 powder on the melting point of the material. The authors found that the melting point increases with the number of build cycles, as illustrated in Figure 18. Higher melting points require larger pre-heating temperatures which increase chances of degradation of powder [8].

A study by Mwania et al. [46] illustrated that the sintering window of PP powder decreases after the first re-use cycle (Fig. 19). This phenomenon is attributed to degradation and cross-linking of the long carbon chains. A converse phenomenon was also observed by Dadbakhsh et al. [39] who investigated the effects of re-use cycles on the sintering window for PA 12 powder. The difference between the two materials might be ascribed to the differences in changes of the long carbon chains when subjected to high temperatures. Figure 20 shows that the gap between melting and crystallization points is wider for aged powder than that for virgin materials. The sintering window affects the cooling rate of printed parts. Materials with larger sintering windows exhibit even cooling rates. 
Melt point Change 0ver 7 Cycle

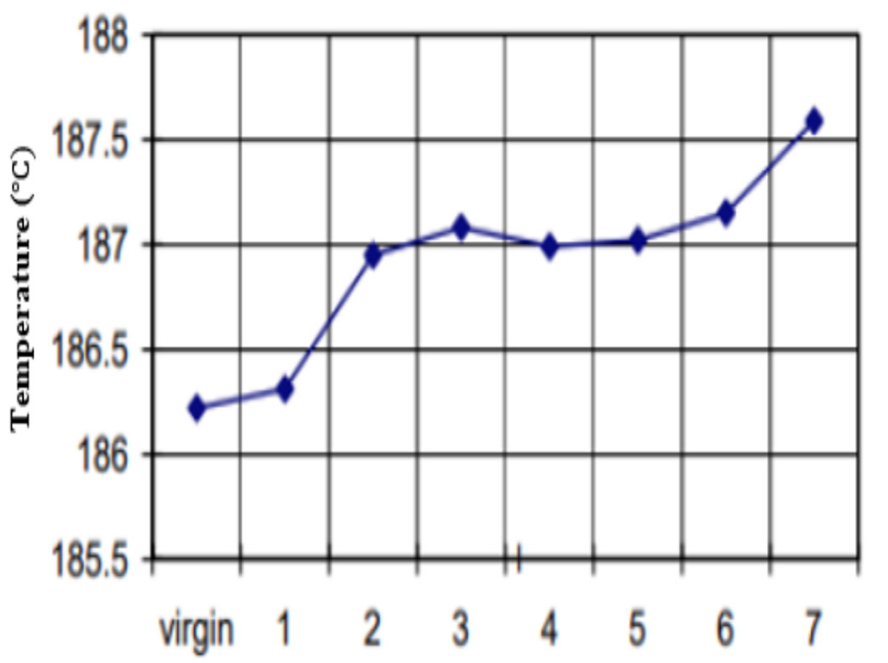

Build

Fig. 18. Melting points of PA 12 with re-use cycles [48].

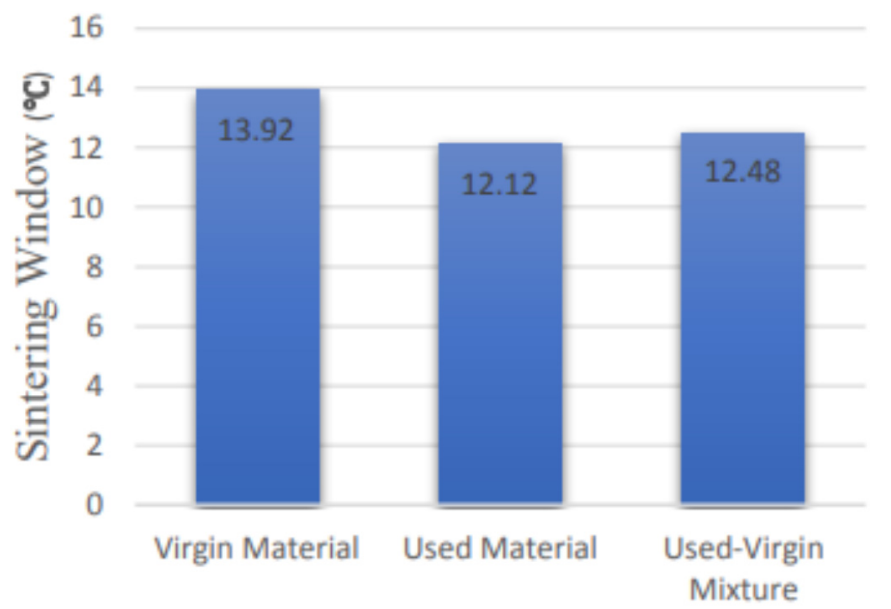

Material Batch

Fig. 19. The sintering window of the PP virgin, used, and usedvirgin mixture powders [46].

Hence, a larger sintering window decreases curling and shrinkages rates of printed parts.

\subsection{Effects of PLS re-use cycles on the mechanical properties of parts printed using polymeric powder materials}

Re-use of polymeric materials affects the mechanical properties of printed parts. Dadbakhsh et al. [39] found that ultimate tensile stress and elongation of PA 12 reduced after aging, but adding fresh materials ameliorates the properties, as illustrated in Table 4.

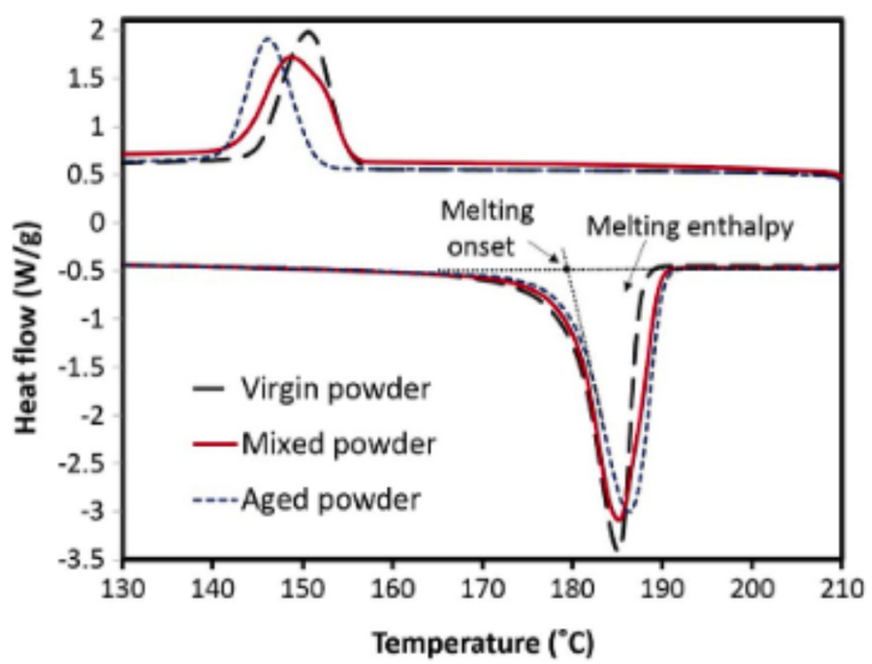

Fig. 20. DSC thermogram for virgin, aged and mixed PA 12 powder [39].

Table 4. Tensile and elongation to break (\%) for virgin, aged, and mixed PA 12 powder.

\begin{tabular}{lll}
\hline PLS part & UTS (MPa) & $\begin{array}{l}\text { Elongation } \\
\text { to break (\%) }\end{array}$ \\
\hline Virgin & $32.7 \pm 2.9$ & $18.5 \pm 2.3$ \\
Mixed & $32.2 \pm 1.1$ & $22.1 \pm 1.4$ \\
Aged & $25.2 \pm 1.9$ & $15.4 \pm 0.8$ \\
\hline
\end{tabular}

Another study by Wegner and Ünlü [51] found that mechanical properties of parts produced using PP powder decrease with the number of re-use cycles (Fig. 21). The magnitude of the mechanical factors is also significantly influenced by the energy density of the laser beam used. Thus, suitable process parameters should be utilized when printing polymeric materials.

\section{Limitations of existing methods of characterizing powders and future works}

MFI and DSC testing are the most commonly used techniques for quantifying the degradation of PLS polymeric powders. However, the two approaches yield limited information on the materials tested; hence, the need for more comprehensive and easier-to-use technologies for this purpose. In this regard, this paper considers previous work conducted by Amado et al. [5]. The authors introduced a new technology for characterization of powder (Revolution Powder Analyzer) that investigates the dynamic behaviour of powder. The aim of the technique was to replace the conventional methods with a more efficient powder characterization strategy. The equipment used in this method consists of a rotating drum manufactured from aluminium with an inner diameter of $50 \mathrm{~mm}$ and a width of $25 \mathrm{~mm}$. The sides of the drum are 

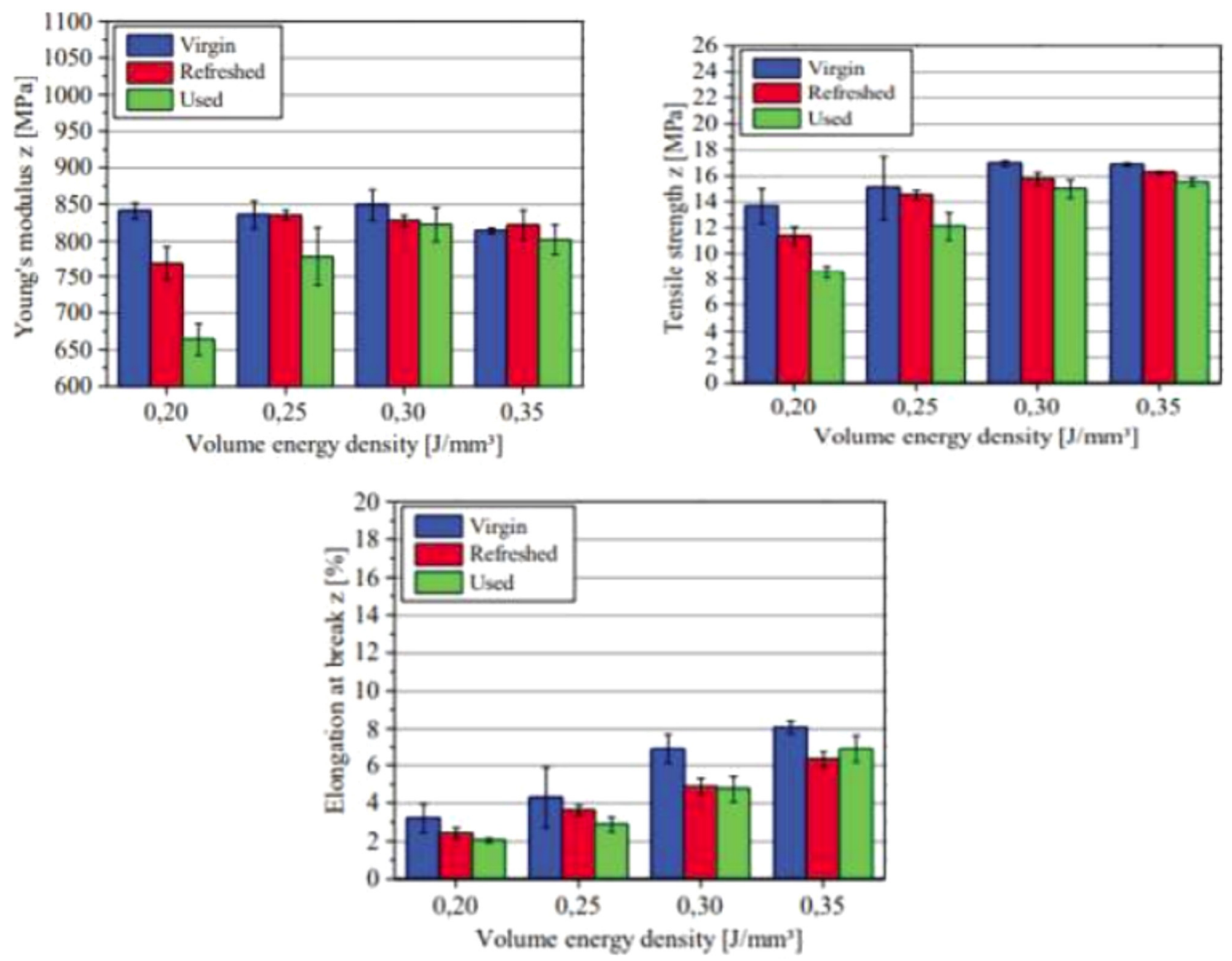

Fig. 21. Effects of the number of re-use cycles on the mechanical properties of polypropylene powder [51].

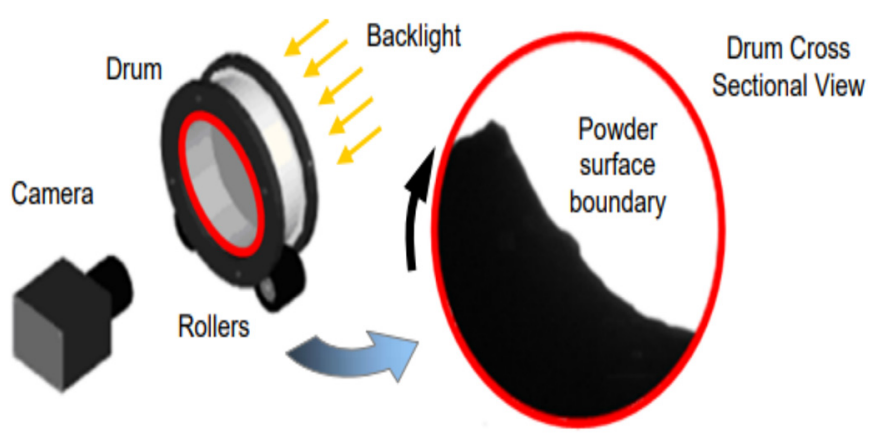

Fig. 22. The proposed powder testing technology by Amado et al. [5].

covered with a transparent glass to allow capturing of the behaviour of powder using an image acquisition system. The drum can rotate at different speeds $(0-200 \mathrm{rpm})$ when conducting experiments. At low speeds the machines records flowability while at high speeds it tests for fluidization properties. The technology can also capture images (morphology) and particle size and distribution of the powder particles. An image of this equipment set-up is shown in Figure 22. The authors of this study proposed that future advances in the characterization of powders should focus on developing simple and easy-to-use mechanisms that can determine a wide array of intrinsic and extrinsic properties of PLS polymers, since the traditional methods determine a limited set of characteristics.

\section{Conclusions}

- There is a need to characterize virgin as well as used PLS polymeric powders to establish their suitability before using or re-using, because it has been established that the PLS process affects the physical, rheological and thermal properties of the polymeric powders.

- Polymer laser sinter recycling of PA 12 powder has been shown to affect the mechanical properties, surface finish and dimensional accuracy of PLS printed parts. 
- There are a number of methods currently in use to characterize polymer powders for PLS including differential scanning calorimetry (DSC), thermogravimetric analysis (TGA), laser diffraction analysis, gas pycnometry, scanning electron microscopy (SEM) and melt flow index (MFI) testing.

- Amongst these methods, the melt flow index (MFI) and differential scanning calorimetry (DSC) are the most commonly utilized techniques.

- However, these two methods do not yield sufficient data to fully quantify the degree of degradation of polymeric powder exposed to PLS. Hence, there is a need for more comprehensive and easier-to-use technologies that test a wider scope of parameters.

- The need to develop new technologies capable of testing a wide array of intrinsic and extrinsic properties of powders is underscored.

\section{Abbreviations}

$\begin{array}{ll}\text { AM } & \text { Additive Manufacturing } \\ \text { PLS } & \text { Polymer Laser Sintering } \\ \text { PA 12 } & \text { Polyamide 12 (Nylon) } \\ \text { PP } & \text { Polypropylene } \\ \text { DSC } & \text { Differential Scanning Calorimetry } \\ \text { TGA } & \text { Thermogravimetric Analysis } \\ \text { SEM } & \text { Scanning Electron Microscopy } \\ \text { MFI } & \text { Melt Flow 1ndex } \\ \text { GPC } & \text { Gel Permeation Chromatography } \\ \text { Td } & \text { Degradation Temperature } \\ T_{m} & \text { Onset of Melting Point } \\ T_{c} & \text { Onset of Crystallization Point } \\ C_{\%} & \text { Degree of Crystallization } \\ \Delta H_{m} & \text { Experimental Melting Enthalpy } \\ \Delta H_{m}^{0} & \text { Literature Melting Enthalpy }\end{array}$

\section{Competing interests}

The authors declare that they have no competing interests.

\section{Funding}

The review was supported by the Collaborative Program in Additive Manufacturing. (Contract No. CSIR-NLC-CPAM15-MOA-CUT-01).

The financial support from the South African Research Chairs Initiative of the Department of Science and Technology and National Research Foundation of South Africa (Grant No. 97994) and the Collaborative Program in Additive Manufacturing (Contract No. CSIR-NLC-CPAM-15-MOA-CUT-01) is gratefully acknowledged. Thanks also to the Centre of Rapid Prototyping and Manufacturing (CRPM) for technical support.

\section{Author contribution statement}

All the authors were involved in development and editing of the report. Besides, all authors read and approved the final manuscript.

\section{References}

1. M. Schmid, K. Wegener, Additive manufacturing: polymers applicable for laser sintering (LS), Procedia Eng. 149 (2016) 457-464

2. U.M. Dilberoglu, B. Gharehpapagh, U. Yaman, M. Dolen, The role of additive manufacturing in the era of industry 4.0 , Procedia Manuf. 11 (2017) 545-554

3. D. Drummer, S. Greiner, M. Zhao, K Wudy, A novel approach for understanding laser sintering of polymers, Addit. Manuf. 27 (2019) 379-388

4. H. Zhang, S. LeBlanc, Processing Parameters for Selective Laser Sintering or Melting of Oxide Ceramics. In: Additive Manufacturing of High-performance Metals and AlloysModeling and Optimization. Intech Open, 2018, vol. 10 1-44

5. A. Amado, M. Schmid, G. Levy, K. Wegener, Advances in SLS powder characterization. 7 (2017) 12-25

6. Y. Yamauchi, T. Niino, T. Kigure, Influence of process time and geometry on part quality of low-temperature laser sintering. Paper presented at the 2017 International Solid Freeform Fabrication Symposium on Additive Manufacturing, Austin, Texas, 7-9 August 2017

7. P. Mägi, A. Krumme, M. Pohlak, Material recycling and improvement issues in additive manufacturing. Paper presented at the 10th International DAAAM Baltic Conference on Industrial Engineering, Tallinn, Estonia, 12-13 May 2015

8. R.D. Goodridge, C.J. Tuck, R.J.M. Hague Laser sintering of polyamides and other polymers, Prog. Mater. Sci. 57 (2012) 229-267

9. D. Drummer, K. Wudy, M. Drexler, Influence of energy input on the degradation behavior of plastic components manufactured by selective laser melting, Phys. Procedia 56 (2014) 176-183

10. J.A. Slotwinski, E.J. Garboczi, P.E. Stutzman, C.F. Ferraris, S.S. Watson, M.A. Peltz, Characterization of metal powders used for additive manufacturing, J. Res. Natl. Inst. Stand. Technol. 119 (2016) 460-475

11. M. Saffarzadeh, G.J. Gillispie, P. Brown, Selective laser sintering (SLS), rapid prototyping technology, a review of medical applications. 1 (2016) 1-21

12. A. Nazarov, I. Skornyakov, I. Shishkovsky, The setup design for selective laser sintering of high-temperature polymer materials with the alignment control system of layer deposition, Machines 6 (2015) 1-11

13. T.M. Marin, Selective laser sintering of polyolefins. Master's thesis, Tampere University of Technology, 2017

14. K. Wudy, D. Drummer, M. Drexler, Characterization of polymer materials and powders for selective laser melting. Paper presented at the 4th International Conference on Mathematics and Natural Sciences, Rhodes, Greece, 22-28 September 2014

15. D.T. Pham, K.D. Dotchev, W.A.Y. Yusoff, Deterioration of polyamide powder properties in the laser sintering process. J. Mech. Eng. Sci. 222 (2008) 2163-2176 
16. M.B. Sagar, K. Elangovan, Consolidation \& factors influencing sintering process in polymer powder based additive manufacturing. Paper presented at the IOP Conference Series: Materials Science and Engineering on Alloys and Experimental Mechanics, Narsimha Reddy Engineering College, India, 3-4 July 2017

17. M. Schmid, A. Amado, K. Wegener, Polymer powders for selective laser sintering (SLS). Paper presented at the 30th International Conference of the Polymer Processing, Cleveland, Ohio, USA, 6-12 June 2015

18. N. Mys, A. Verberckmoes, L. Cardon, Expanding the material palette for Selective Laser Sintering: two production techniques for spherical powders. Paper presented at the International Conference on Polymers and Moulds Innovations-PMI on Additive Manufacturing, Institute of Education, University of Minho, Portugal, 19-21 September 2018

19. A.T. Sutton, C.S. Kriewall, M.C. Leu, J.W. Newkirk, Powder characterisation techniques and effects of powder characteristics on part properties in powder-bed fusion processes, Virtual Phys. Prototy. 12 (2017) 3-29

20. S. Berretta, O. Ghita, K.E. Evans, A. Anderson, C. Newman, Size, shape and flow of powders for use in Selective Laser Sintering (SLS). In: High Value Manufacturing: Advanced Research in Virtual and Rapid Prototyping 49 (2013) 1-7

21. M. Schmid, K. Wegener, Thermal and molecular properties of polymer powders for Selective Laser Sintering (SLS). Paper presented at the AIP Conference Proceedings on Polymer Processing Society, Graz, Austria, 21-25 September 2015

22. D. Drummer, D. Rietzel, F. Kühnlein, Development of a characterization approach for the sintering behavior of new thermoplastics for selective laser sintering, Phys. Procedia 5 (2010) 533-542

23. G.M. Craft, Characterization of nylon-12 in a novel additive manufacturing technology, and the rheological and spectroscopic analysis of PEG-starch matrix interactions. Dissertation, University of South Florida (2018)

24. Y. Khalil, N. Hopkinson, A. Kowalski, J.P.A. Fairclough, Characterisation of UHMWPE polymer powder for laser sintering, Materials 12 (2019) 3496-3516

25. S. Tamari, A. Aguilar-Chavez, Optimum design of gas pycnometers for determining the volume of solid particles, J. Test. Eval. 33 (2005) 1-5

26. J. Bodycomb, Laser Diffraction Theory When a Light beam Strikes a Particle (Horiba, Kyoto, 2012)

27. G. Eshel, G.J. Levy, U. Mingelgrin, M.J. Singer, Critical evaluation of the use of laser diffraction for particle-size distribution analysis, Soil Sci. Soc. Am. J. 68 (2004) 737-743

28. J.A. Seyforth, Scanning Electron Microscopy (SEM). An introduction to the use of SEM for characterizing the surface topology and composition of matter with further applications Scanning Electron Microscopy (SEM), Exp. Tech. Condens. Matter Phys. 2 (2015) 13-27

29. W. Zhou, R. Apkarian, Z.L. Wang, D. Joy, Fundamentals of Scanning Electron Microscopy (SEM), In: Scanning Microscopy for Nanotechnology: Techniques and Applications, 2007, vol. 1, 1-40

30. S. Berretta, O. Ghita, K.E. Evans, Morphology of polymeric powders in Laser Sintering (LS): from polyamide to new PEEK powders, Eur. Polym. J. 59 (2014) 218-229
31. O.P. Choudhary, P. Choudhary, Scanning electron microscope: advantages and disadvantages in imaging components, Int. J. Curr. Microbiol. Appl. Sci. 6 (2017) 1877-1882

32. C. Schick, Differential scanning calorimetry (DSC) of semicrystalline polymers, Anal. Bioanal. Chem. 395 (2009) $1589-1611$

33. J. Janečková (n.d.) Thermal analysis techniques. Retrieved from https://slideplayer.com/slide/16978195/ (Accessed on 24 Jan 2020)

34. A. Askadskiı̌, Computational Materials Science of Polymers. (Great Abington, Cambridge, 2003)

35. International Association of Plastics Distribution. (n.d.) International Association of Plastics Distribution - Typical Properties of Polypropylene. Retrieved from http://www. sdplastics.com/pdf/pp.pdf (Accessed on 24 Jan 2020)

36. F.M. Mwania, M. Maringa, J.G. van der Walt, A review of methods used to reduce the effects of high temperature associated with polyamide 12 and polypropylene laser sintering, Adv. Polym. Technol. 2020 (2020) 1-11

37. K. Dotchev, W. Yusoff, Recycling of polyamide 12 based powders in the laser sintering process, Rapid Prototyp. J. 15 (2009) 192-203

38. S. Rüsenberg, R. Weiffen, F. Knoop, H.J. Schmid, M. Gessler, H. Pfisterer, Controlling the quality of laser sintered parts along the process chain. Paper presented at the 23rd International Solid Freeform Fabrication Symposium (SFF 2012) on Additive Manufacturing, University of Texas at Austin, USA, 3-6 August 2012

39. S. Dadbakhsh, L. Verbelen, O. Verkinderen, D. Strobbe, P. Van Puyvelde, J.P. Kruth, Effect of PA12 powder reuse on coalescence behaviour and microstructure of SLS parts, Eur. Polym. J. 92 (2017) 250-262

40. S. Park, J.W. Hwang, K.N. Kim, G.S. Lee, J.H. Nam, Rheology and curing characteristics of dual-curable clearcoats with hydroxyl functionalized urethane methacrylate oligomer: effect of blocked isocyanate thermal crosslinkers Rheology and curing characteristics of dual-curable clearcoats with hydroxyl functionalized urethane methacrylate oligomer: Effect of blocked isocyanate thermal crosslinkers, Korea Aust. Rheol. J. 26 (2014) 159-167

41. K. Wudy, D. Drummer, Aging behavior of polyamide 12: interrelation between bulk characteristics and part properties. Paper presented at the Solid Freeform Fabrication Symposium on Additive Manufacturing, University of Texas at Austin, USA, 7-10 August 2016

42. M. Schmid, F. Amado, G. Levy, K. Wegener, Flowability of powders for selective laser sintering (SLS) investigated by round robin test. Paper Presented in High Value Manufacturing: Advanced Research in Virtual and Rapid Prototyping: Proceedings of the 6th International Conference on Advanced Research in Virtual and Rapid Prototyping, pp. 1-5, 2013

43. T. Laumer, T. Stichel, K. Nagulin, M. Schmidt, Optical analysis of polymer powder materials for selective laser sintering, Polym. Test. 56 (2016) 207-213

44. S.C. Ligon, R. Liska, J. Stampfl, M. Gurr, R. Mülhaupt, Polymers for 3D printing and customized additive manufacturing, Chem. Rev. 117 (2017) 10212-10290

45. O.R. Ghita, E. James, R. Trimble, K.E. Evans, Physicochemical behaviour of poly (ether ketone) (PEK) in high temperature laser sintering (HT-LS), J. Mater. Process. Technol. 214 (2014) 969-978 
46. F.M. Mwania, M. Maringa, J.G. van der Walt, Powder characterization for a new selective laser sintering polypropylene material (Laser PP CP 60) after single print cycle degradation, Int. J. Eng. Res. Technol. 13 (2020) 3342-3358

47. S. Rüsenberg, S. Josupeit, H.J. Schmid, A method to characterize the quality of a polymer laser sintering process, Adv. Mech. Eng. 6 (2014) 74-87

48. T.J. Gornet, K.R. Davis, T.L. Starr, K.M. Mulloy, Characterization of selective laser sintering materials to determine process stability. Paper presented in Solid Freeform Fabrication Symposium, Austin 1 (2002) 546-553
49. R.G. Kleijnen, M. Schmid, K. Wegener, Production and processing of a spherical polybutylene terephthalate powder for laser sintering, Appl. Sci. 9 (2019) 1308-1329

50. S. Aldahsh, Dependence of SLS parameters on thermal properties of composite material of cement with polyamide 12, J. Appl. Mech. Eng. 2 (2013) 1-7

51. A. Wegner, T. Ünlü, Powder life cycle analyses for a new polypropylene laser sintering material. Paper presented at the 27th Annual International Solid Freeform Fabrication Symposium on Additive Manufacturing, 27, 834-846, 2016

Cite this article as: Fredrick Mulinge Mwania, Maina Maringa, Jacobus G. van der Walt, A review of the techniques used to characterize laser sintering of polymeric powders for use and re-use in additive manufacturing, Manufacturing Rev. 8, 14 (2021) 